\title{
On Upward Swirling Liquid Film in Gas-liquid Pipe Compact Separator
}

\author{
Sunday Kanshio \\ Department of Petroleum and Gas Engineering, Baze University, Abuja, Nigeria
}

Email address:

sunday.kanshio@bazeuniversity.edu.ng

\section{To cite this article:}

Sunday Kanshio. On Upward Swirling Liquid Film in Gas-liquid Pipe Compact Separator. Petroleum Science and Engineering. Vol. 3, No. 2, 2019, pp. 39-45. doi: 10.11648/j.pse.20190302.12

Received: July 24, 2019; Accepted: August 13, 2019; Published: August 29, 2019

\begin{abstract}
This paper presents experimental findings on upward swirling liquid film for both single-phase and two-phase gas-liquid flow in a vertical gas-liquid cyclonic separator. The upward swirling liquid film is one dynamic phenomenon that occurs in pipe cyclonic separator. The upward swirling of the liquid film in the upper part of the cyclonic separator is the primary source of liquid entrainment into the gas core. Liquid entrainment from the separator wall into the gas core is the main cause of liquid carryover. Liquid carryover is the major disadvantage of the gas-liquid pipe cyclonic separator. Various researchers in the past have identified the effect of this phenomenon on the performance of gas-liquid pipe cyclonic separator, but not many efforts have been made to study the phenomenon in detail. In this work, the upward swirling liquid film height was measured using a meter rule, while the thickness of the swirling liquid film was estimated using the void fraction that was measured with electrical resistance tomography (ERT). The experimental results show that the height attained by the upward swirling liquid film is a function of the film thickness and inlet gas velocity. The results also showed that the horizontal inlet pipe produces the highest liquid film height when compared with the inclined inlet pipe. By keeping the liquid flow rate constant and increasing gas flow rate, a maximum liquid film height was observed, afterwards, the liquid film height decreases within increasing gas flow rate.
\end{abstract}

Keywords: Compact Separator, Swirling Liquid Film, Liquid Carryover, Separator Performance, Film Thickness, Gas Superficial Velocity

\section{Introduction}

Compact separators have application in oil and gas production and processing where space and weight are design constraint such as subsea, downhole, floating production vessels, and oil production platforms. Most compact separators use centrifugal force to achieve efficient gas-liquid separation. However, due to the compact nature of the separator, the operating envelope is usually narrow resulting in efficient operation of the separator at high gas/liquid flow. Hence, operating the separator at high liquid/gas flow rate is usually avoided to minimise liquid carryover (LCO) into the gas outlet. Liquid carryover is therefore a fundamental issue regarding the design and operation of compact separators [12]. The upward swirling liquid film (USLF) is known to be a source of liquid entrainment into the gas stream [1-4]. Liquid entrainment in the gas is generally identified to be the primary cause of liquid carryover. The USLF is the liquid film that climbs towards the gas outlet of the separator while swirling on the cylindrical wall. A photo and schematic drawing of this phenomenon is presented in Figure 1. The USLF phenomenon is very complicated; considering climbing and falling film flow happens at the same time. Depending on the inlet flow condition, the swirling film could ascend the pipe wall up to a certain height; then reverse and descend to join the downward falling film. This height is what is referred to as USLF height. During the adverse operating condition, the height attained by the USLF could be as high as the separator gas outlet. Yue et al., recently studied the flow regimes associated with the USLF experimentally and numerically, but there was no data on the height of the USLF [6]. Researchers have made efforts to design film removal devices to extract the liquid film from the separator wall to increase the operating envelope of the separator to minimise the effect of the USLF on liquid carryover. For example, Molina et al., reported an increase in 
separation efficiency of a GLCC separator whose upper part was modified by installing two annular film extractor (AFE) [7]. The AFE were respectively installed at $406.4 \mathrm{~mm}$ and $762 \mathrm{~mm}$ below the top GLCC separator. The question is: How were these two positions determined?

At present, there is no recommended guideline or correlation for estimating the height at which such device

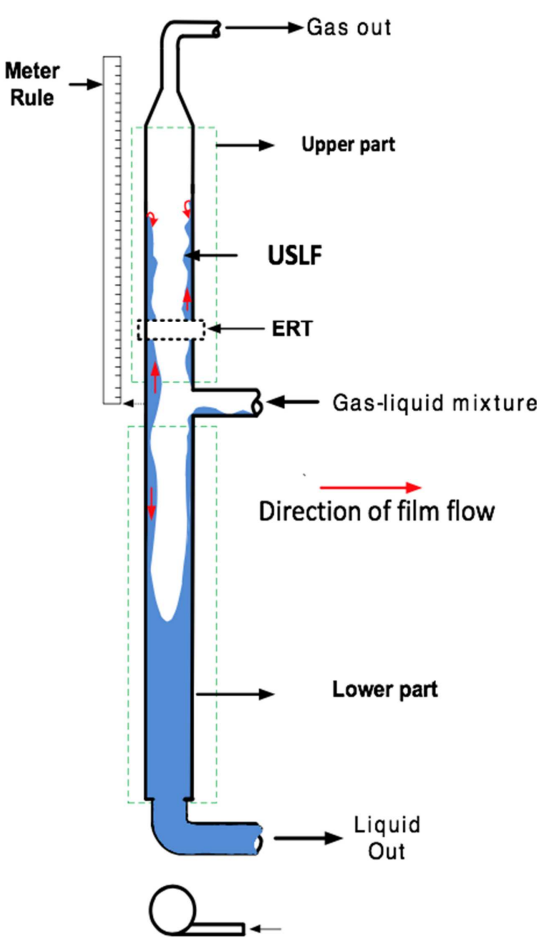

Figure 1. USLF in horizontal inlet gas-liquid pipe cyclonic (GLPC) separator.

\section{Experimental Setup and Procedure}

\subsection{Test Facility}

To study the upward swirling liquid film characteristics and develop a correlation for estimating the maximum height the film will attain while climbing the separator wall, a gas-
Therefore, adopting this technology to similar separator but of different height may not be a difficult task. Therefore, the maximum height the USLF could attain for every inlet condition before droplet entrainment is initiated the need to be investigated. This information may be useful as a guideline in specifying the height at which similar devices could be installed in GLCC separator.

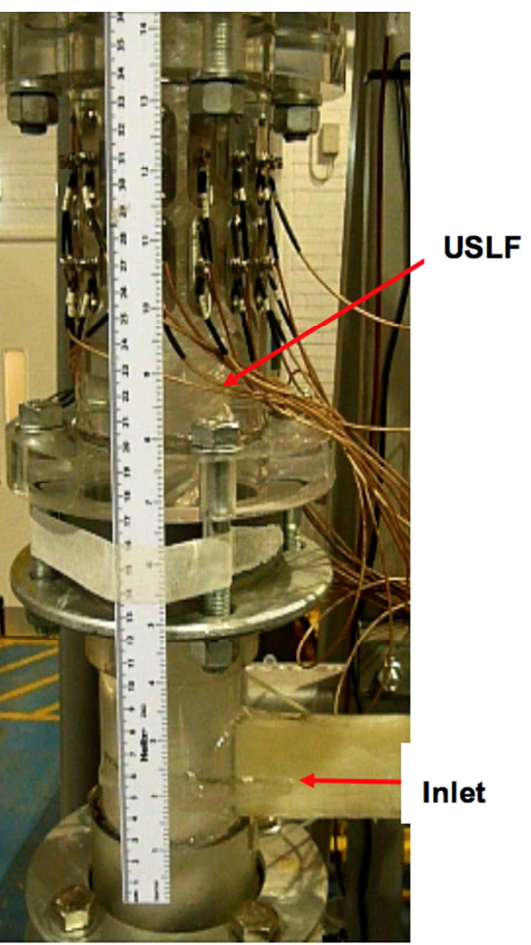

liquid pipe cyclone (GLPC) separator test facility is at Cranfield University, UK. As shown in Figure 2, the test facility is a closed loop system consisting of the fluids supply and metering section; GLPC separator, and fluids return section. Air and water were used as test fluids and referred to as gas and liquid, respectively in this work.

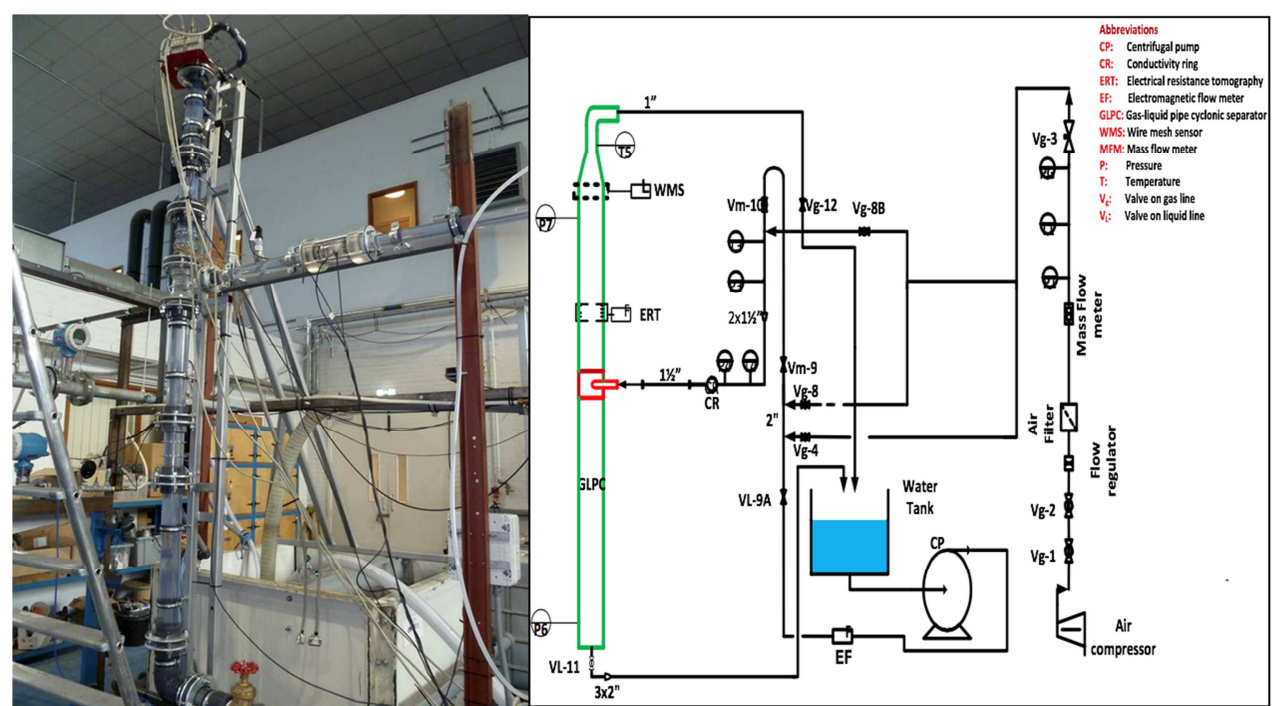

Figure 2. Experimental setup. 
Table 1. Dimension of GLPC separator.

\begin{tabular}{ll}
\hline Parts & Dimension (mm) \\
\hline Separator diameter & 76.10 \\
Inlet pipe diameter & 38.10 \\
Gas outlet diameter & 25.40 \\
Liquid outlet diameter & 50.80 \\
Height above inlet & 1300 \\
Height below inlet & 1600 \\
\hline
\end{tabular}

The gas (air) was metered using Endress+Hauser thermal mass flow meter (Proline t-mass 65) before entering. Water was supplied to the flow loop by Certikin Aquaspeed selfpriming pump which has a maximum duty of $41 / \mathrm{s}$ at 3 barg. It was metered using $\mathrm{ABB}$ electromagnetic flow meter.

The test section consists mainly of a horizontal inlet GLPC separator where the separation of gas from the liquid takes place. The separator dimension is as shown in Table 1.

The separator inlet nozzle was varied to investigate their

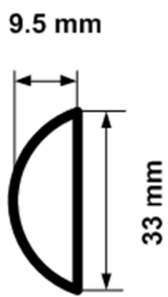

D-Noz-1

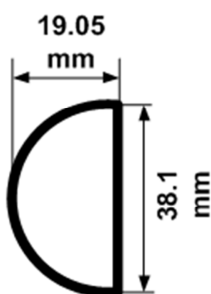

D-Noz-2 effect on the upward swirling liquid film. These devices were carefully installed in the separator inlet and were aligned with the wall of the separator to give a D-shape inlet nozzle. Two basic principles underpinned the inlet nozzle design: to reduce the inlet flow area and initiate angular momentum at the inlet. Reducing the flow area of the tangential inlet will eventually increase the velocity of the fluids at the inlet nozzle that would translate into high centrifugal force. Initiating angular momentum at the inlet by forcing the flow to the outer wall of the inlet pipe would potentially increase swirling intensity in the separator. Each of these devices has two sides: the flat and curved side. The flat side has a longtapered end to convey the flow into the reduced flow area gently. Since these three inlet nozzles have the shape of Dshape, they are being referred to respectively as D-Noz-1 and D-Noz-2. The schematic drawing of the inlet nozzles opening, and the isometric view is presented in Figure 3.

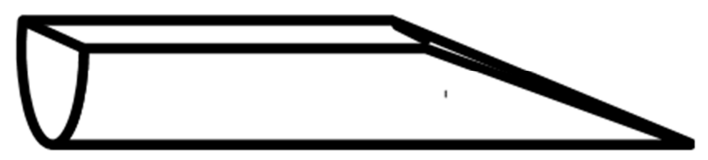

Isometric View of the insert

Figure 3. GLPC separator inlet nozzle.

\subsection{Instrumentation and Data Acquisition}

The instruments used for this research include pressure transducer, temperature probe and electrical resistance tomography (ERT). The ERT was used for online flow imaging, offline image reconstruction and measurement of cross-sectional liquid holdup in the separator. The ERT is installed above the separator inlet at $250 \mathrm{~mm}$ and $830 \mathrm{~mm}$ respectively.

The ERT is a non-intrusive measurement technique by which information about the electrical properties of fluids in a process volume is inferred from the periphery electrodes measurement. The ERT used in this study consist of a dualplane sensor each having 16 stainless steel electrodes mounted on the periphery of the GLPC separator. A data acquisition system (DAS) developed by ITS Plc was used to acquire data from the sensor. The data acquisition and transfer speed of the system was approximately 1000 frames per second. The sensitive coefficient back projection algorithm was used for image reconstruction.

The wall pressure fluctuation in the separator was measured using fast response pressure. The pressure transducer used has a rangeability of 0-6 barg. The pressure transducer was used to confirm the wire mesh sensor measurement.

\subsection{Experimental Procedure}

Single-phase liquid flow: To understand the relationship between inlet liquid flow rate and the height attained by the upward swirling film, single-phase liquid flow USLF experiment was conducted. Starting with the low liquid flow rate and gradually increasing it stepwise, the USLF was observed. The USLF height $\left(\mathrm{H}_{\mathrm{sf}}\right)$ for each liquid flow was established by reading off the corresponding level on the meter rule that was fastened to the separator body.

Two-phase gas-liquid flow: This experiment was conducted for the actual phase separation operating condition of the separator. The experiment was carried out in a similar procedure as the single-phase liquid flow. Before conducting the actual phase separation experiment, the stable $\mathrm{H}_{\mathrm{sf}}$ for that single-phase liquid flow was first established and recorded to determine the film height before introducing gas. Starting with a low gas flow rate at a fixed liquid flow rate, the steady $\mathrm{H}_{\mathrm{sf}}$ was established and recorded. The gas flow rate was then increased, and the same procedure, as stated above, was repeated. The gas flow rate was increased until the available gas capacity of the facility was exhausted or until churn flow was observed in the upper part of the separator. A higher liquid flow rate was then introduced into the separator, and the same procedure explained above repeated. 
Table 2. Experimental uncertainty.

\begin{tabular}{lll}
\hline Instrument/Apparatus & Parameter & Uncertainty/errors \\
\hline Thermal mass flowmeter & Air mass flow & $\pm 1.5 \%$ of full of scale \\
Electromagnetic flowmeter & Water flow rate & $\pm 0.5 \%$ of full scale \\
Pressure transducer & The inlet pipe and separator pressure & $\pm 0.15 \%$ of full scale \\
ERT & Separator liquid holdup & $48-60 \%$ for void fraction above 0.2 \\
Conductivity ring probe & Inlet pipe liquid holdup & $\pm 2 \%$ Based on bench calibration \\
Meter rule & USLF height & $\pm 2 \%$ \\
\hline
\end{tabular}

\section{Results and Discussion}

\subsection{Single Phase Liquid Flow}

To evaluate the effect of Froude number on the USLF height during the actual separation process, it is important to first evaluate for single phase liquid flow.

\subsubsection{Effect of Froude Number on USLF Height}

The modified Froude number formula derived by Kanshio is used in this section to evaluate its effect on USLF height $\left(\mathrm{H}_{\mathrm{sf}}\right)$ for single-phase liquid flow [8]. The modified Froude number is used in this study so that the effect of inlet phase velocity, separator inlet orientation angle and separator diameter could be accounted for.

$$
F_{r l}=\frac{\left(\frac{v_{i n} A_{i n}}{A_{n o z}} \cos \theta\right)^{2}}{0.5 g D_{\text {sep }}}
$$

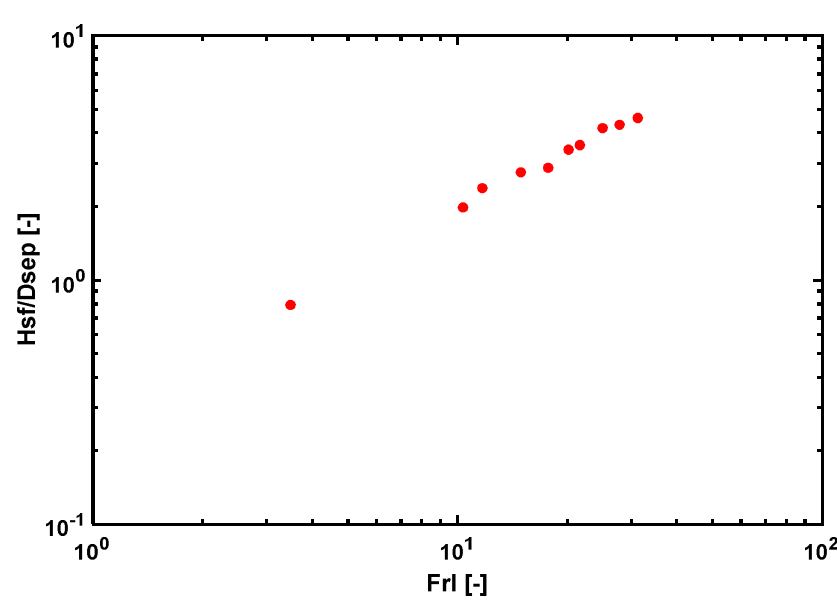

Figure 4. Effect of Froude number on USLF height for horizontal inlet pipe (Nozzle diameter $=$ Inlet pipe bore).

In Figure 4, the dimensionless USLF height, which is the ratio of USLF height $\left(\mathrm{H}_{\mathrm{sf}}\right)$ to separator diameter $\left(\mathrm{D}_{\text {sep }}\right)$, has been plotted against the Froude number (Equation 1). It is clear from Figure 4 that the dimensionless USLF height increases with increasing Froude number. As the liquid velocity into the separator increases, the tangential velocity increases in the same proportion, thereby creating a stronger centrifugal force field on the liquid film in both upward and downward flow direction. Additionally, because of the sudden expansion of the flow area from inlet nozzle to the separator body, the liquid will have to spread-out over the separator wall due to the low pressure downstream of the inlet nozzle. Increasing Froude number increases the liquid spread, and hence more liquid film swirls upwardly towards the gas outlet until a point where the swirl decays due to wall friction and interfacial shear stress.

\subsubsection{Effect of Inlet Pipe Orientation and Nozzle Geometry on USLF Height}

There is evidence in the literature that inlet nozzle size and shape have an effect on the performance of gas-liquid cyclonic separator concerning liquid carry over [6-9]. Though, Hreiz observed that too severe converging inlet nozzle destabilised USLF, but there were no sufficient data to back-up this claim [3]. Since USLF is a source of liquid carryover, further effort is made in the present research to study the effect of the inlet nozzle cross-section on USLF height. The nozzles used for this study are D-Noz-1 and DNoz-1. A detail about the inlet pipe and the nozzles is presented in Chapter 3.

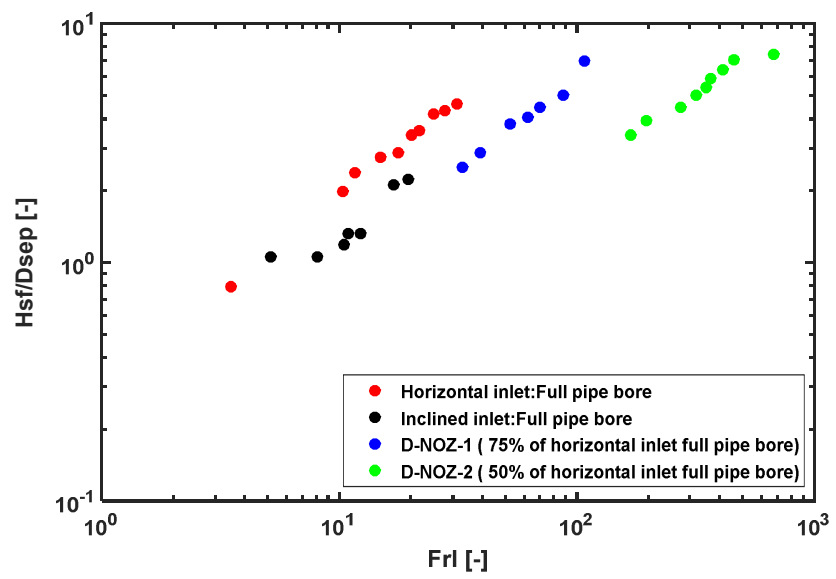

Figure 5. Effect of Froude number and nozzle geometry on USLF height.

In Figure 5, the dimensionless USLF height increases consistently with increasing Froude number for both inlet pipe orientation and inlet nozzle cross sectional area as expected. The dimensionless USLF height in the case of the inclined inlet was generally less than that of the horizontal inlet for the same inlet pipe velocity (see Table 3). This is because the liquid is introduced below the inlet pipe centreline; hence, the gravitation effect reduces the climbing of the film, and the tangential velocity is reduced. The use of the D-shape inlet nozzle tends to increase the dimensionless USLF height as the cross-sectional area of the inlet nozzle decreases. This is due to the high nozzle exit velocity that causes the film to spread wider on entering the separator. As shown in Table 3, though reducing the inlet nozzle cross- 
sectional area increases the tangential velocity, the corresponding increase in dimensionless USLF height is marginal. This is expected because of high-pressure drop across the inlet nozzle caused by a further restriction in separator entrance cross sectional area.

Table 3. Effect of inlet pipe orientation and inlet nozzle size on dimensionless USLF height.

\begin{tabular}{|c|c|c|c|c|c|c|c|c|}
\hline \multirow[b]{2}{*}{ Inlet nozzle type } & \multirow[b]{2}{*}{ Inlet pipe orientation } & \multirow[b]{2}{*}{$v_{i n}$} & \multirow[b]{2}{*}{$v_{t}$} & \multirow[b]{2}{*}{$H_{s f}$} & \multirow{2}{*}{$\frac{H_{s f}}{D_{s e p}}$} & \multirow[b]{2}{*}{$\boldsymbol{F} \boldsymbol{r}_{l}$} & \multicolumn{2}{|c|}{ *Percentage increase $(\mathrm{X} 100 \%)$} \\
\hline & & & & & & & $\frac{H_{s f}}{D_{s e p}}$ & $\boldsymbol{F r}_{l}$ \\
\hline Full bore & Horizontal & 2.74 & 2.74 & 0.26 & 3.42 & 20.15 & - & - \\
\hline D-Noz-1 & Horizontal & 2.71 & 4.82 & 0.31 & 4.07 & 62.32 & 0.19 & 2.09 \\
\hline D-Noz-2 & Horizontal & 2.73 & 10.93 & 0.38 & 4.99 & 319.87 & 0.46 & 14.88 \\
\hline Full bore & $27^{0}$ inclined & 2.86 & 2.55 & 0.17 & 2.23 & 19.56 & -1.18 & -0.03 \\
\hline
\end{tabular}

*Full bore horizontal inlet is used as the base case

\subsubsection{Effect of Reynolds Number on USLF Height}

Viscosity has a remarkable effect on the performance of gasliquid cyclone [9-11]. Also, as reported by Zhao et al., and Archibong-Eso et al., pressure gradient increases with oil viscosity due to an increase in shear stress [12, 13]. Since Reynolds number account for the viscous effect on the flow characteristics, its effect on USLF height has been evaluated and presented in Figure 6. The Reynolds number was calculated based on tangential velocity and separator diameter as:

$$
R e=\frac{\rho_{l} v_{t} D_{s e p}}{\mu_{l}}
$$

where $\rho_{l}, V_{T}, D_{\text {sep }}$ and $\mu_{l}$ liquid density, tangential velocity, separator diameter and liquid viscosity.

It can be seen in Figure 6, which the dimensionless film generally increases with increasing Reynolds number in a similar trend as that of the Froude number. This is because of the inertia effect rather than the viscous effect since the liquid viscosity is constant. However, increasing viscosity may likely cause a decrease in USLF height because of the increase in wall shear.

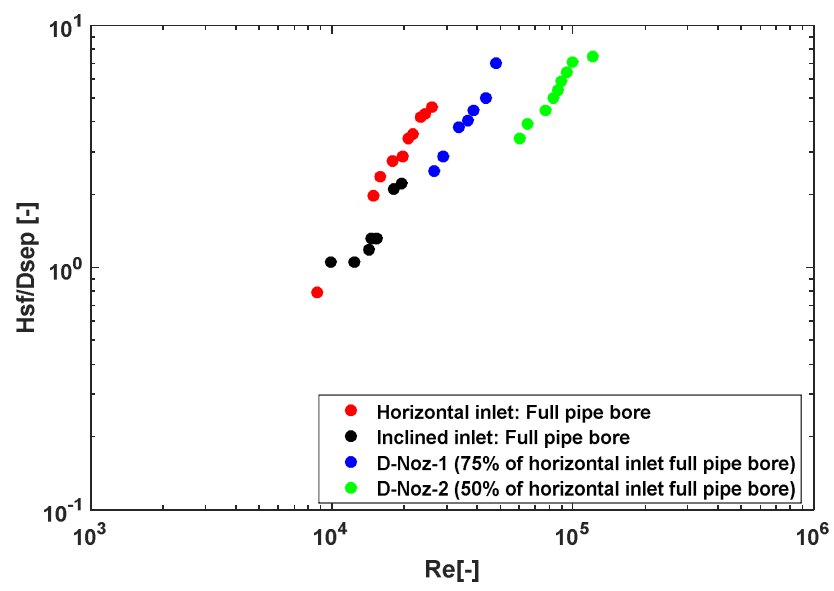

Figure 6. Effect of Reynolds number and nozzle geometry on USLF height.

From the single-phase liquid experimental results and analysis presented, it is clear that irrespective of inlet pipe orientation and nozzle geometry, the USLF height is a function of both Froude and Reynolds number of the liquid at the separator entrance as given in Equation 1 and 2. This function is expressed in Equation 3.

$$
\frac{H_{s f}}{D_{s e p}}=f(R e, F r)
$$

\subsection{Two-Phase Flow-USLF Height}

Since the separator is a two-phase separator, the height at which the upward liquid film attends was studied by introducing gas to obtain a two-phase flow. The dynamics of USLF for gas-liquid two-phase flow in the separator shares some similarity with that of single-phase liquid flow, as explained in section 3.2. However, the presence of the gas phase introduces complex dynamics into the USLF phenomenon. The nature of radial liquid holdup profile and film thickness behaviour is first examined to understand its contribution to USLF height.

\subsubsection{Upward Liquid Film Thickness}

The upward swirling liquid film thickness was estimated from the void fraction obtained from the ERT system by applying the well-known geometry relationship given in Equation 4. Many researchers have used this relationship in estimating film thickness; a relatively recent example is that by Kaji et al., [16]. In using this relationship, it was assumed that the liquid film is smooth and uniformly distributed on the separator wall.

$$
\delta=\frac{1}{2} D_{s e p}(1-\sqrt{\alpha})
$$

where $\delta, D_{\text {sep }}$ and $\alpha$ are film thickness, separator diameter and void fraction respectively.

The average time series of the liquid film thickness is presented in Figure 7, and Figure 8 shows that the USLF is inherently wavy and generally fluctuates because of simultaneous climbing and falling film phenomena as well as flow instability in the inlet pipe. The average film thickness increases from $4 \mathrm{~mm}$ to $7 \mathrm{~mm}$ corresponding to an increase in inlet superficial gas velocity from $4.56 \mathrm{~m} / \mathrm{s}$ to $7.52 \mathrm{~m} / \mathrm{s}$. In the case of the superficial gas velocity of $4.56 \mathrm{~m} / \mathrm{s}$, the separation process was more efficient; hence, a significant amount of the liquid was drained as the multiphase mixture enters the separator. In the case of the superficial gas velocity of $7.52 \mathrm{~m} / \mathrm{s}$, the film is thicker because of inefficient separation resulting in more liquid in the upper part of the separator. 


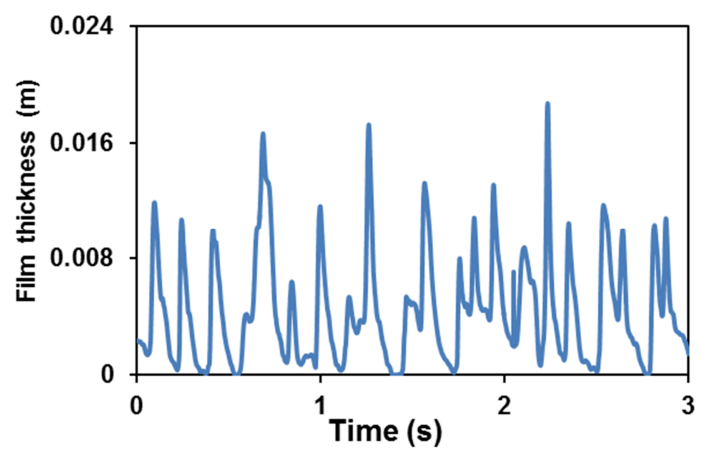

Figure 7. Upper swirling film thickness for Usg=4.56 m/s and Usl $=2.52 \mathrm{~m} / \mathrm{s}$ $\delta_{a v}=4 \mathrm{~mm}$.

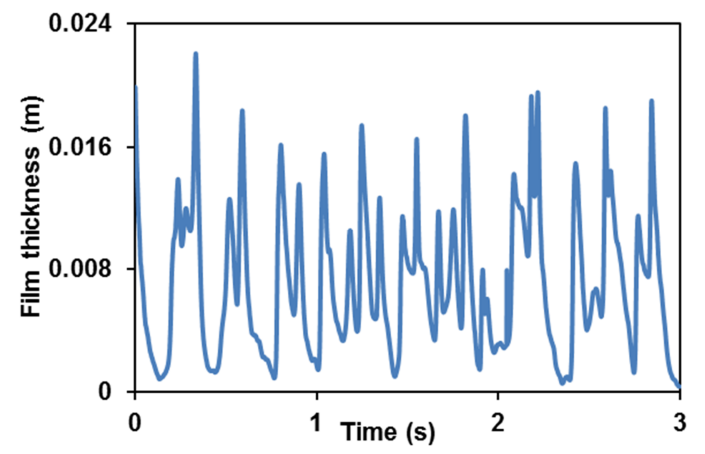

Figure 8. Upper swirling film thickness for Usg $=7.52 \mathrm{~m} / \mathrm{s}$ and Usl $=2.52$ $\mathrm{m} / \mathrm{s}: \delta_{a v}=7 \mathrm{~mm}$.

\subsubsection{Maximum USLF Height}

The dimensionless USLF height $\left(\mathrm{H}_{\mathrm{sf}} / \mathrm{D}_{\text {sep }}\right)$ as a function gas Froude number $\left(\mathrm{Fr}_{\mathrm{g}}\right)$ and liquid Froude number $\left(\mathrm{Fr}_{\mathrm{l}}\right)$ is presented in this section. The maximum $\mathrm{H}_{\text {sf }} / \mathrm{D}_{\text {sep }}$ is obtained from the maximum height at which the USLF attained a constant liquid flow rate. Using Equation 1, the gas and liquid Froude number were estimated, respectively. As can be seen in Figure 9 and Figure 10, the plot of $\mathrm{H}_{\mathrm{sf}} / \mathrm{D}_{\text {sep }}$ against Froude number has two sides demarcated by a maximum $\mathrm{H}_{\mathrm{sf}} / \mathrm{D}_{\text {sep }}$ points (shown by red dots). On the left side of the maximum $\mathrm{H}_{\mathrm{sf}} / \mathrm{D}_{\text {sep }}$, the dimensionless USLF height increases steadily with increasing $\mathrm{Fr}_{\mathrm{g}}$ for a constant $\mathrm{Fr}_{1}$ because of drag force exerted by the rising gas on the liquid film. On the right of the maximum $\mathrm{H}_{\mathrm{sf}} / \mathrm{D}_{\text {sep }}$, the dimensionless USLF height generally decreases with an increase in gas flow rate into the separator. Two possible phenomena could justify this decrease in dimensionless USLF height: Liquid film drainage effect and film stripping, as explained below.

Liquid film drainage effect: At intermediate to high liquid superficial velocities $\left(\mathrm{U}_{\mathrm{SL}}=2.14 \mathrm{~m} / \mathrm{s}\right.$ to $\left.3.77 \mathrm{~m} / \mathrm{s}\right)$, the weight of the liquid film increases due to increase in the thickness of the swirling film and hence the drag force of the gas is not enough to sustain the film on the separator wall. Therefore, the liquid film descends and drains faster under the influence of gravity. Also, the swirling intensity of the gas decayed faster due to interfacial friction. Generally, the variation in $\mathrm{H}_{\mathrm{sf}} / \mathrm{D}_{\text {sep }}$, as well as maximum Hsf/Dsep, is not high. The maximum $\mathrm{H}_{\mathrm{s} f} / \mathrm{D}_{\text {sep }}$ shown by the red dots in Figure 9 were collected, and the $3 \mathrm{D}$ surface plot was generated, as shown in Figure 10. The 3D plot supports the fact that the maximum
$\mathrm{H}_{\mathrm{s}} / \mathrm{D}_{\text {sep }}$ under this condition does not vary much (ranging from 5.52 to 7.75), having a standard deviation of 0.71 and a mean of 6.67. In fact, the 3D surface plot is relatively flat with slightly high peaks at the highest gas Froude number (far right).

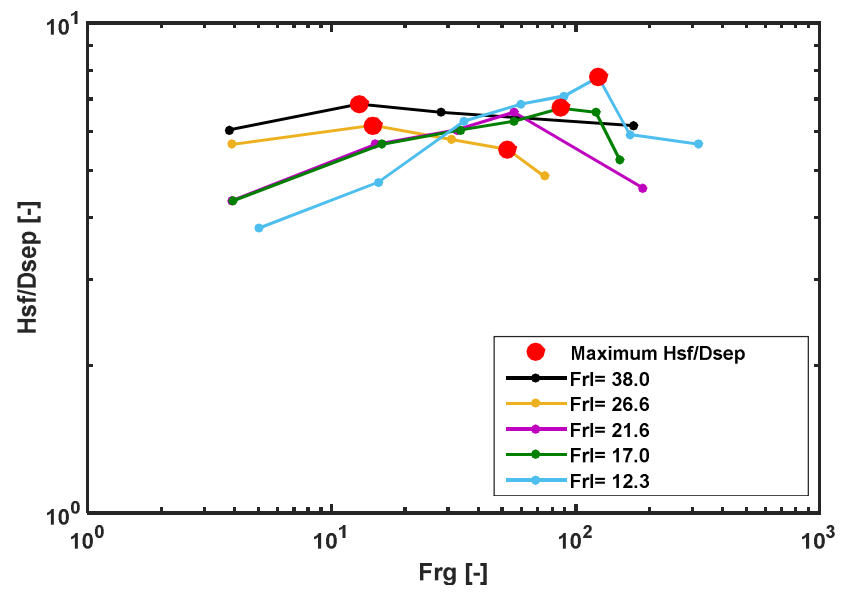

Figure 9. Dimensionless USLF height as a function of gas and liquid Froude flow for $U_{S L}=2.14 \mathrm{~m} / \mathrm{s}$ to $3.77 \mathrm{~m} / \mathrm{s}$.

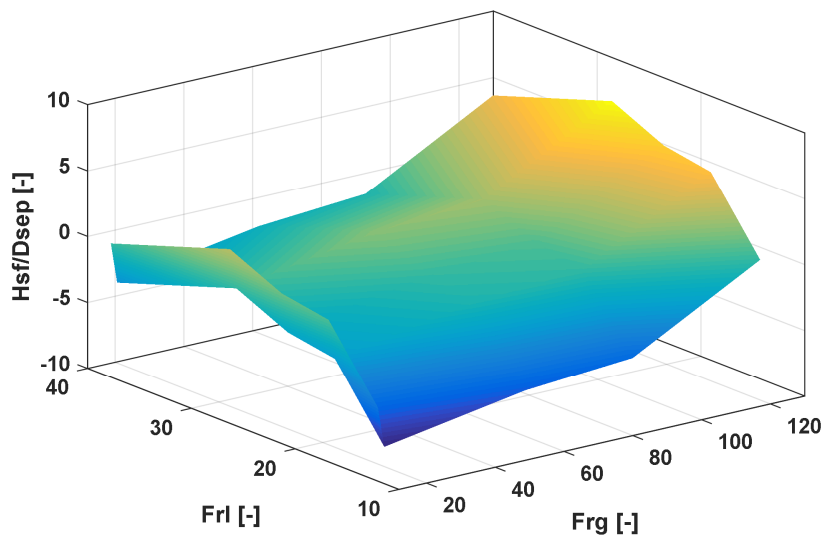

Figure 10. 3D surface plot of Maximum USLF height as a function of liquid and gas Froude number for $U S L=2.14 \mathrm{~m} / \mathrm{s}$ to $3.77 \mathrm{~m} / \mathrm{s}$.

Film stripping effect: At low to intermediate superficial liquid velocities (USL=2.14 m/s to $3.77 \mathrm{~m} / \mathrm{s}$ ), the swirling film in thinner and unstable. However, the gas drags the film upward due to stronger near wall axial velocity, resulting in higher maximum $\mathrm{H}_{\mathrm{sf}} / \mathrm{D}_{\text {sep. }}$. Due to the wavy nature of the gasliquid interface, the rising gas undercuts through the wave crest, pulls the liquid into the centre core, and drags it upward. It is believed that this phenomenon reduces the USLF height in lesser magnitude compared to the drainage effect. As can be seen in Figure 11, the variation in $\mathrm{H}_{\mathrm{sf}} / \mathrm{D}_{\text {sep }}$, as well as maximum Hsf/Dsep, is higher compared to liquid film drainage effect. The maximum $\mathrm{H}_{\mathrm{sf}} / \mathrm{D}_{\text {sep }}$ shown by the red dots in Figure 11 were collected, and the 3D surface plot was generated, as shown in Figure 12. The 3D plot showed an appreciable variation in the maximum $\mathrm{H}_{\mathrm{s}} / \mathrm{D}_{\text {sep. }}$ The maximum $\mathrm{H}_{\mathrm{sf}} / \mathrm{D}_{\text {sep }}$ ranges from 6.83 to 9.72 , having a standard deviation of 1.26 and a mean of 8.28 . 


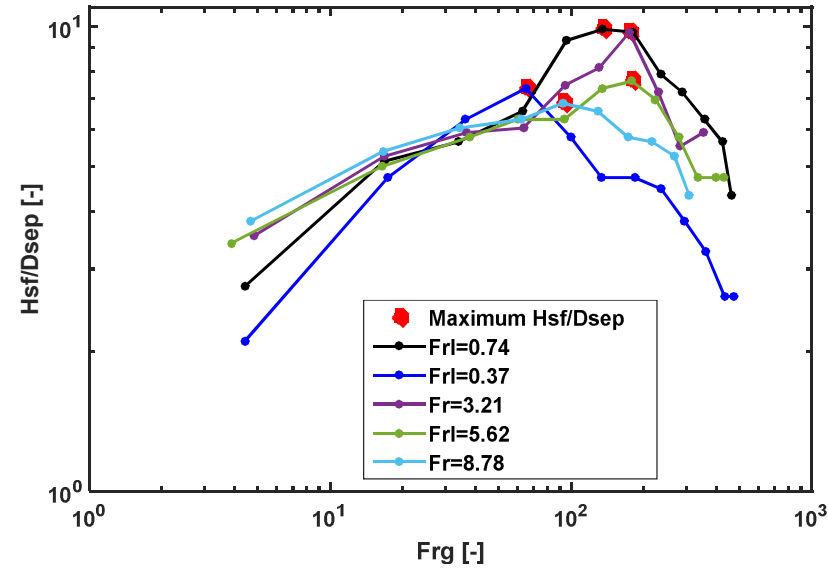

Figure 11. Dimensionless USLF height as a function of gas and liquid Froude flow for $U S L=0.37 \mathrm{~m} / \mathrm{s}$ to $1.81 \mathrm{~m} / \mathrm{s}$.

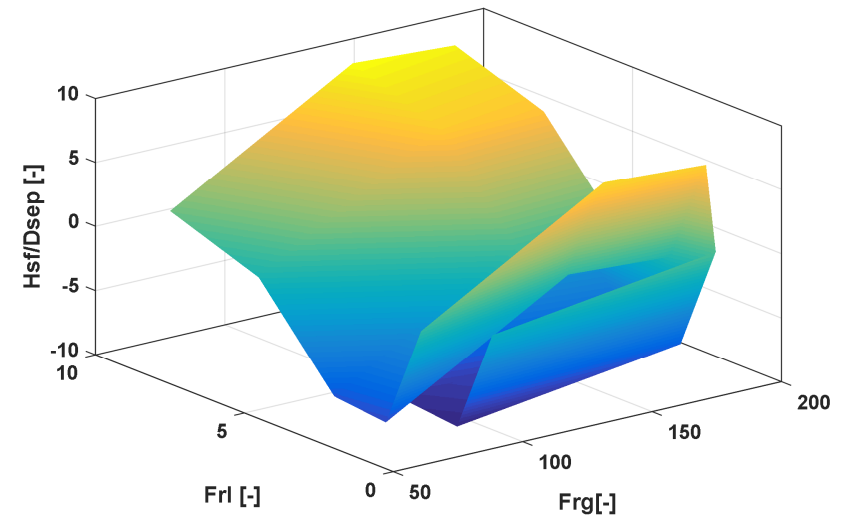

Figure 12. 3D surface plot of Maximum USLF height as a function of liquid and gas Froude number for $U S L=0.37 \mathrm{~m} / \mathrm{s}$ to $1.81 \mathrm{~m} / \mathrm{s}$.

\section{Conclusion}

In this work, the result of an experimental investigation of USLF height has been presented for both single-phase liquid flow and gas-liquid two-phase flow. The effect of Froude, Reynolds and Euler number on the dimensionless USLF height was analysed. For single-phase flow, the USLF height was found to increase with inlet liquid velocity. Dimensionless USLF height was found to be a function of both Froude and Reynolds number. The Reynolds and Froude number were calculated based on tangential velocity at the separator entrance. In case of twophase flow, while varying the gas flow rate, a maximum USLF height was found for every liquid flowrate. The USLF height prior to the maximum height showed a similar trend with the single-phase liquid flow. Beyond the maximum height, the USLF height decreases with increasing gas flow rate. The liquid film was estimated based on void fraction and geometry relationship. The film thickness was found to increase with both increases in liquid and gas flow rate. The liquid film was found to be inherently unstable because of simultaneous climbing and falling of the liquid film. The magnitude of the fluctuation reduces, as the film gets thicker.

\section{References}

[1] S. S. Kolla, R. S. Mohan, and O. Shoham, "Mechanistic Modeling of Liquid Carry-Over for 3-Phase Flow in GLCCC Compact Separators," no. 51555. p. V001T06A017, 2018.

[2] S. Kanshio, H. Yeung, and L. Lao, "Study of phase distribution in pipe cyclonic compact separator using wire mesh sensor," Flow Meas. Instrum., vol. 53, 2017.

[3] R. Hreiz, R. Lainé, J. Wu, C. Lemaitre, C. Gentric, and D. Fünfschilling, "On the effect of the nozzle design on the performances of gas-liquid cylindrical cyclone separators," Int. J. Multiph. Flow, vol. 58, pp. 15-26, Jan. 2014.

[4] A. Pollak, "The separation of liquid from vapor, using cyclones..." 1941.

[5] L. E. Polyakov, "Cyclone separators for gas-liquid mixtures," Chem. Pet. Eng., vol. 4, no. 6, pp. 460-462, 1968.

[6] T. Yue et al., "Experimental and numerical study of Upper Swirling Liquid Film (USLF) among Gas-Liquid Cylindrical Cyclones (GLCC)," Chem. Eng. J., vol. 358, pp. 806-820, 2019.

[7] R. Molina, S. Wang, L. E. Gomez, R. S. Mohan, O. Shoham, and G. Kouba, "Wet Gas Separation in Gas-Liquid Cylindrical Cyclone Separator," J. Energy Resour. Technol., vol. 130, no. 4, p. 042701, 2008.

[8] S. Kanshio, "Multiphase flow in pipe cyclonic separator," Cranfield University, 2015.

[9] F. M. Erdal and S. A. Shirazi, "Effect of the Inlet Geometry on the Flow in a Cylindrical Cyclone Separator," J. Energy Resour. Technol., vol. 128, no. 1, p. 62, 2006.

[10] I. Uvwo, "Expanding the Operational Envelope of Compact Cylindrical Cyclone Gas / Liquid Separators Using a Variable Inlet-Slot Configuration Expanding the Operational Envelope of Compact Cylindrical Cyclone Gas / Liquid Separators Using a Variable Inlet-Slot Confi," no. December, 2004.

[11] R. Hreiz, R. Lainé, J. Wu, C. Lemaitre, C. Gentric, and D. Fünfschilling, "On the effect of the nozzle design on the performances of gas-liquid cylindrical cyclone separators," Int. J. Multiph. Flow, vol. 58, pp. 15-26, Jan. 2014.

[12] N. Barbuceanu, S. Scott, A. Texas, and S. Scott, "SPE 71555 Novel Inlet Design Expense Range of Operability for Compact Separator," Spe 71555, 2001.

[13] S. Movafaghian, J. a Jaua-marturet, R. S. Mohan, and O. Shoham, "The effects of geometry, fluid properties and pressure on the hydrodynamics of gas-liquid cylindrical cyclone separators," vol. 26, pp. 999-1018, 2000.

[14] Y. Zhao, H. Yeung, E. E. Zorgani, A. E. Archibong, and L. Lao, "High viscosity effects on characteristics of oil and gas two-phase flow in horizontal pipes," Chem. Eng. Sci., vol. 95, pp. 343-352, May 2013.

[15] A. Archibong-Eso, W. Yan, Y. Baba, S. Kanshio, and H. Yeung, Viscous Liquid-Gas Flow in Horizontal Pipelines: Experiments and Multiphase Flow Simulator Assessment, no. 3. BHR Group, 2015, pp. 283-296.

[16] R. Kaji and B. J. Azzopardi, "The effect of pipe diameter on the structure of gas/liquid flow in vertical pipes," Int. J. Multiph. Flow, vol. 36, no. 4, pp. 303-313, Apr. 2010. 